\title{
CURRÍCULOS E FORMAÇÕES DE PROFESSORES: SOBRE A FORÇA DAS NARRATIVAS E DAS REDES COTIDIANAS
}

\author{
CURRICULUMS AND TEACHER TRAINING: ON THE STRENGTH OF NARRATIVES \\ AND DAILY NETWORKS
}

\author{
CURRÍCULOS Y FORMACIONES DE PROFESORES: SOBRE LA FUERZA DE \\ NARRATIVAS Y REDES COTIDIANAS
}

Carlos Eduardo Ferraço

Universidade Federal do Espírito Santo - Brasil

Danielle Piontkovsky

Instituto Federal do Espírito Santo - Brasil

Maria Regina Lopes Gomes

Universidade Vila Velha - Brasil

\begin{abstract}
Resumo: Com a escrita deste artigo buscamos enunciar que os processos de tessituras curriculares e de formações de professores, em nossos estudos, são pensados de modo interdependente, considerando as inventividades e produções dos diferentes praticantes que habitam os cotidianos das escolas públicas onde realizamos as pesquisas. Com esses sujeitos praticantes e suas narrativas, procuramos transitar nas redes que tecem currículos e processos de formações, prestando atenção nas pistas deixadas a partir dos usos que fazem dos discursos oficiais, resultando, muitas vezes, em movimentos de resistência a esses discursos que, de certo modo, negligenciam e/ou desqualificam o que é realizado nas escolas. Defendemos, portanto, a importância de pensar os temas currículo e formação de professores como processos complexos e interdependentes, que dizem respeito à produção e à negociação de políticas educacionais que não se reduzem às prescrições oficiais, geralmente marcadas pelas lógicas dos distanciamentos e da negação das produções docentes, assim como pela ideia de uniformização dos currículos escolares. Assumimos, como perspectiva teórico-epistemológicometodológica, as redes de conhecimento e as práticas de pesquisa com os cotidianos, buscando problematizar os conhecimentos tecidos nas ações cotidianas a partir das narrativas, usos $e$ negociações que os praticantes fazem dos textos prescritivos, produzindo, nesse contexto, políticas educacionais. Apostamos, assim, que as práticas-políticas de currículos produzidas nessas tessituras se constituem como possibilidades de alargamento das experiências vividas entre os praticantes das escolas nos diferentes contextos culturais que habitam, indicando processos inventivos efetivados em redes compartilhadas de conhecimentos.
\end{abstract}

Palavras-chave: Cotidianos. Currículos. Formação docente.

Abstract: The concepts of educational processes and teacher training in our studies are thought in an interdependent way, considering how inventions and productions of different practitioners that inhabit the daily life of public schools where we conduct research. With these practitioners and their 
narratives, we try to transit in networks that weave curricula and training processes, paying attention to the clues left from the official discourses uses that often result in movements of resistance to these discourses that, somehow, neglect and / or disqualify what is done in schools. We therefore defend the importance of thinking about curriculum and teacher education as complex and interdependent processes, which concern the production and negotiation of educational policies that are not reduced to the official prescriptions, usually marked by the logics of distancing and denying as well as the idea of standardizing school curricula. We assume, as a theoretical-epistemological-methodological perspective, the knowledge networks and the research practices within the everyday life, seeking problematize the knowledges woven in everyday actions from the narratives, uses and negotiations that practitioners make of the prescriptive texts, producing, in this context, educational policies. We argue, thereby, that the policy practices of curricula produced in these conjunctures are constituted as possibilities to widen the living experiences between the practitioners of the schools in the different cultural contexts that they inhabit, indicating inventive processes carried out in shared networks of knowledge.

Keywords: Daily routines. Curriculums. Teacher training.

Resumen: Con la escritura de este artículo buscamos enunciar que los procesos de tesitura curriculares y de formaciones de profesores, en nuestros estudios, son pensados de modo interdependiente, considerando las inventividades y producciones de los diferentes practicantes que habitan los cotidianos de las escuelas públicas donde realizamos las investigaciones. Con estos sujetos practicantes y sus narrativas, buscamos transitar en las redes que tejen los currículos y los procesos de formaciones, prestando atención a las pistas dejadas a partir de los usos que hacen de los discursos oficiales, resultando, muchas veces, en movimientos de resistencia a esos discursos que, en cierto modo, descuidan y / o descalifican lo que se realiza en las escuelas. Defendemos, por lo tanto, la importancia de pensar los temas currículo y formación de profesores como procesos complejos e interdependientes, que se refieren a la producción y a la negociación de políticas educativas que no se reducen a las prescripciones oficiales, generalmente marcadas por las lógicas de los distanciamientos y de la negación de las producciones docentes, así como por la idea de uniformización de los currículos escolares. En el caso de las mujeres, en el caso de las mujeres, la mayoría de las veces, la mayoría de las veces, la mayoría de las veces, contexto, políticas educativas. Por lo tanto, apostamos a que las prácticas políticas de currículos producidas en estas tesis se constituyen como posibilidades de ampliación de las experiencias vividas entre los practicantes de las escuelas en los diferentes contextos culturales que habitan, indicando procesos inventivos efectivos en redes compartidas de conocimientos. Tomamos como perspectiva teórica, epistemológica, metodológica las redes de conocimiento y las prácticas de investigación con los cotidianos, buscando problematizar los conocimientos tejidos en las acciones cotidianas a partir de las narrativas, usos y negociaciones que los practicantes hacen de los textos prescriptivos, produciendo, en ese contexto, políticas educativas. Por lo tanto, apostamos a que las prácticas políticas de currículos producidas en estas tesituras se constituyen como posibilidades de ampliación de las experiencias vividas entre los practicantes de las escuelas en los diferentes contextos culturales que habitan, indicando procesos inventivos efectivos en redes compartidas de conocimientos.

Palabras clave: Cotidianos. Currículos. Formación docente.

\section{Continuando algumas conversas...}

Com a escrita desse artigo buscamos pensar as práticas de currículo e de formações de professores nos enredamentos que as constituem, compreendendo com Certeau (1994) a força das práticas como políticas dos cotidianos. Por essa razão, teorizações dos estudos dos 
cotidianos (CERTEAU, 1994) foram escolhidas para nos acompanhar nessa produção, reconhecendo que nos cotidianos estão coexistindo as múltiplas dimensões e circunstâncias de constituição dessas práticas-políticas pedagógicas que se tecem nas redes de saberes, fazeres, valores, poderes, afetos, sentidos, culturas docentes entre tantas outras.

Dessa maneira, assumimos, com esse autor, as noções de política, de cotidiano e de uma política do cotidiano, uma vez que nos interessam as operações dos usuários e as “[...] 'maneiras diferentes de marcar socialmente o desvio' operado num dado por uma prática [...]". Sendo assim, a 'proliferação disseminada' de criações anônimas e 'perecíveis' que irrompem com vivacidade e não se capitalizam" (GIARD, 1994, p. 13) se tornam permanentes "encantamentos" de nossas pesquisas.

Usando as aprendizagens com Certeau (1995) e a sua proposição de pensar uma cultura no plural, que não está isenta de ligações políticas, defendemos, nas pesquisas que realizamos nas redes municipal e federal da educação básica, uma política de educação que também se coloca no plural. Ou seja, que se situa para além das tentativas de interpretações unitárias e das homogeneidades produzidas e impostas pelas tecnicidades do Estado (CERTEAU, 1995), agenciando modos outros com os quais os homens inventam sua própria liberdade e criam para si um espaço de movimentação.

Assim, o presente texto tem como objetivo trazer elementos para a ampliação da discussão que associa práticas curriculares a processos de formações de professores, a partir de algumas narrativas dos diferentes praticantes que habitam nos cotidianos das escolas públicas onde realizamos as pesquisas. Ou seja, dada à condição de complexidade ${ }^{1}$ desses conhecimentos, torna-se impossível, em meio a essas redes, saber quando estamos vivendo processos curriculares e/ou de formações.

Com esses sujeitos praticantes (CERTEAU, 1994) e suas narrativas, portanto, procuramos transitar nas redes que tecem currículos e processos de formações, prestando atenção nas pistas que estão presentes a partir dos usos que fazem dos discursos oficiais, resultando, em muitos casos, em movimentos de resistência a esses discursos que, de certo modo, negligenciam e/ou desqualificam o que é realizado nas escolas.

Vale aqui afirmar que nossos processos de constituição docente foram e são tecidos em meio às mazelas e belezas que pulsam na vida de escolas, daí nossa gratidão aos colegas de profissão, às crianças, adolescentes e jovens que, nos encontros diários das aulas, têm produzido redes curriculares que afirmam docências, que permanentemente inventam e

\footnotetext{
${ }^{1}$ Estamos partindo da ideia de complexidade defendida por Morin (2007), ou seja, complexo porque está sendo tecido junto.
} 
evidenciam a força dos cotidianos das escolas, apesar das inúmeras tentativas de regulação, silenciamentos dos professores e de padronização curricular que temos vivido e enfrentado nesses nossos tempos...

Mesmo considerando a força e a importância desses discursos que, na maioria das vezes, se pretendem hegemônicos, interessa-nos, em nossas pesquisas, uma maior aproximação dos conhecimentos tecidos em redes nos cotidianos das escolas, os quais, ao mesmo tempo, produzem currículos em suas relações com processos de formação docente, em contraposição às políticas educacionais atuais que têm desconsiderado e desvalorizado as produções das escolas públicas e as lutas de seus professores.

Assim sendo, defendemos a importância de pensar os temas currículo e formação de professores como processos complexos e interdependentes, que dizem respeito à produção e à negociação de políticas educacionais que não se reduzem às prescrições oficiais, geralmente marcadas pelas lógicas dos distanciamentos e polarizações entre pensar e agir, saber e fazer, teoria e prática. Lógicas que têm se mostrado incapazes de dar conta da diversidade e da complexidade das relações que se tecem nos cotidianos escolares.

Desse modo, em função das apostas ético-políticas das pesquisas, defendemos uma legitimação das diferenças e acasos e incompletudes e imprevistos e belezas e desafios como fios de redes que inventam cotidianamente as escolas e desobedecem aos modelos impostos, por exemplo, pela Base Nacional Curricular Comum e pela "Reforma" do Ensino Médio, além de outras tentativas de silenciamento, negação das produções docentes e ideia de uniformização dos currículos escolares.

A nosso ver, são nas negociações, usos e narrativas dos fazeressaberes dos sujeitos que praticam os cotidianos escolares que os currículos e os processos de formações vão se tecendo e, ao mesmo tempo, produzindo políticas educacionais. Assim, Sgarbi (2004) também nos ajuda nessa defesa quando afirma que a complexidade, como marca do mundo real e das pessoas reais, traz uma percepção de que a dinâmica da vida é diferente dos estudos sobre a vida. [...] "por isso, devem ser respeitados no que trazem de possibilidades de leituras do mundo, mas sem a costumeira ideia da hegemonia do pensamento moderno de que, se alguma coisa da vida não cabe nas explicações, ela não existe” (SBARBI, 2004, p.36).

Partindo dessa compreensão, reconhecendo a força dos encontros e, ao mesmo tempo, a impossibilidade de darmos conta dos múltiplos sentidos e significados que as narrativas dos praticantes cotidianos (CERTEAU, 1994) nos indicam sobre seu fazer curricular e sobre as práticas de formação que tecem os cotidianos de escolas, podemos afirmar que 
[...] somos nós que decidimos que fios, que lembranças, que relatos, que imagens, que histórias, que sons, sombras e silêncios irão tornar-se "visíveis" aos "olhos" dos nossos leitores [...] então para que a pena nos seja leve, precisamos assumir nossos limites, amarras e impossibilidades não como problemas, mas como condições necessárias aos estudos "com" os cotidianos. Ainda aqui, precisamos assumir nossos textos em sua permanente condição de "discursos inacabados" [...] Discursos que, por mais vivos que possam parecer aos olhos dos leitores/leitoras, ainda estão muito longe de captar toda a intensidade da vida cotidiana. Os cotidianos pulsam muito mais fortemente do que qualquer análise que façamos "com" eles. (FERRAÇO, 2003, p. 171-2).

Concordando com a ideia de que a dinâmica da vida não se deixa aprisionar facilmente, pois a vida escapa e se inventa com movimentos táticos, efêmeros, surpreendentes dos sujeitos, tratamos das discussões de constituição dos currículos compreendendo que, ao falar deles, também falamos das formações docentes, ou seja, não estamos tratando de pólos dicotômicos de análise, ao contrário, para nós, esses processos só podem ser pensados nos enredamentos que os constituem, num constante trançardestrançar dos conhecimentos enredados nos espaçostempos das escolas e, por efeito, da vida (FERRAÇO, 2006). Processos vividos que envolvem fios das diferenças culturais, das invenções, das múltiplas e singulares enunciações que acontecem com os sujeitos praticantes das escolas e que ajudam a produzir políticas de currículo e de formações de professores.

\section{As narrativas e conversas como forças políticas das pesquisas com os cotidianos}

A perspectiva epistemológico-metodólogico-política defendida em nossas pesquisas, isto é, assumir a dimensão de complexidade das redes de conhecimentos tecidas nos cotidianos das escolas como potência para entendermos as relações produtoras de políticas de educação estabelecidas entre processos curriculares e de formações, estimula-nos a tentar problematizar os conhecimentos tecidos nas ações cotidianas a partir das narrativas, usos e negociações que os praticantes fazem dos textos prescritivos.

Sendo assim, em nossos estudos, não faz sentido falar sobre as verdades científicas construídas em relação aos currículos e aos processos de formação. Pesquisar sobre traz as marcas do controle do pesquisador que, seguro do lugar que ocupa, domina a cena. No entanto, se "estamos incluídos, mergulhados em nosso objeto, chegando, às vezes, a nos confundir com ele, no lugar dos estudos 'sobre', de fato, acontecem os estudos 'com' os cotidianos. [...] Buscamos nos entender fazendo de conta que estamos entendendo os outros, mas nós somos também esses outros e outros “outros"” (FERRAÇO, 2003, p. 160). 
No lugar de pesquisar sobre nos dedicamos, então, a pesquisar com (FERRAÇO, 2003). Uma escolha que nos move a trabalhar com as narrativas dos sujeitos das escolas como pistas, como possibilidades de identificação/compreensão da produção de políticas de currículo em suas relações com processos de formação. Guimarães (2006) nos lança em direção a esse universo das narrativas que dizem do movimento de uma sociedade que, ao falar, se constitui e se reinventa cotidianamente. Para o autor,

As narrativas constituem o eixo do nosso olhar conhecedor [...]. Com efeito, desde há muito, a vida ordinária, comum a todos os homens, tem sofrido menosprezo daqueles estudiosos que nela enxergaram apenas o predomínio da opinião [...] Quando abordada pelos sociólogos objetivistas, a vida comum é explicada por uma operação científica que a separa dos saberes e dos discursos configuradores das experiências vividas pelos sujeitos. A esta perspectiva objetivista opõem-se as sociologias fenomenológicas que pretendem descortinar, na própria multiplicidade das experiências singulares dos atores e dos agentes, figuras recorrentes que regulem o sentido das ações e dos discursos da experiência cotidiana. (GUIMARÃES, 2006, p. 8-9).

Alves (2005), por sua vez, considera necessário discutir algumas críticas feitas ao uso de narrativas em trabalhos de pesquisadores preocupados com o cotidiano. Uma dessas críticas refere-se à multiplicidade de sentidos que essas situações evocam.

Nessas pesquisas, ouvir uma narrativa [...] traz, a cada um que ouve, dentro das redes de conhecimentos e significados a que pertence, a possibilidade de 'ver', 'sentir', 'entender', e 'ouvir' coisas muito diferentes. A questão é saber se isto significa, apenas, as dificuldades de uso desses recursos ou indica a ampliação de possibilidades na análise de uma dada situação, exigindo que incorporemos, necessariamente, a complexidade e potencialidade que cada acontecimento traz em si. Os que trabalham com as pesquisas nos/dos/com os cotidianos tendem a adotar essa segunda posição (ALVES, 2005, p. 8).

Benjamin (1987) também nos ajuda nessa discussão, ao considerar a potência que a narrativa contempla de intercambiar experiências. Para o autor (1987, p. 198), “[...] a experiência que passa de pessoa a pessoa é a fonte a que recorreram todos os narradores. E, entre as narrativas escritas, as melhores são as que menos se distinguem das histórias orais contadas pelos inúmeros narradores anônimos". Ao tomar as narrativas como algo que se tece no discurso vivo e que, em seu aspecto sensível, não é de modo algum o produto exclusivo da voz, ${ }^{2}$ o autor destaca as dimensões do dom de ouvir e das comunidades dos ouvintes,

\footnotetext{
${ }^{2}$ Benjamin (1987, p. 221) ainda afirma: "Na verdadeira narração, a mão intervém decisivamente, com seus gestos, aprendidos na experiência do trabalho, que sustentam de cem maneiras o fluxo do que é dito".
} 
alertando-nos para a necessidade de uma escuta sensível e atenciosa em relação aos sujeitos dos cotidianos escolares.

É preciso considerar, ainda, que as narrativas tecem, ao mesmo tempo, diferentes lugares praticados pelos sujeitos narradores e diferentes relações de fazeres, saberes e poderes desses narradorespraticantes. Para Alves e Garcia (2002, p. 274-277):

É preciso, pois, que incorporemos a idéia que ao dizer uma história, somos narradores praticantes traçando/trançando as redes dos múltiplos relatos que chegaram/chegam até nós, neles inserindo, sempre, o fio do nosso modo próprio de contar [...]. Nesses espaçostempos cotidianos, a cultura narrativa tem grande importância por garantir formas, de certa maneira, duradouras aos conhecimentos, por poderem ser repetidas e recriadas, isto porque, embora, naturalmente, tenham um conteúdo que não garante a sua fixação, permitem uma ressignificação, uma história diferente das que conhecemos em relação aos conhecimentos científicos ou políticos oficiais, que são sobretudo escritos.

Torna-se importante considerar, ainda, que as pesquisas realizadas com os cotidianos, ao tomarem as narrativas como expressões das redes tecidas nas escolas, acabam envolvendo os próprios pesquisadores nessas redes. Como fala Alves (2005, p. 8), “[...] o pesquisador também não tem condição de fugir dessas redes, pois está nelas mergulhado, interpretando o que lê, com tudo o que tem de encarnado, em si, teorias e conceitos, podendo deixar de ver algo que outro pesquisador veria”.

Assim, as narrativas dos sujeitos das escolas pesquisadas têm se revelado muito mais como potencialidades de expressões das relações, dos fluxos, das redes estabelecidas com a nossa presença do que como identificação e/ou descrição de um fato acontecido tal e qual ocorreu, independente de nós. Isso significa dizer que, de alguma maneira, nós, na condição de pesquisadores com os cotidianos, estamos envolvidos na criação/tessitura das redes de narrativas daqueles momentos, não sendo possível negar que também somos responsáveis pelos conhecimentos que estamos produzindo sobre as escolas com as nossas pesquisas. Tudo isso nos leva a assumir, com Certeau (1994), a nossa condição de pesquisador praticante ${ }^{3}$, à medida que nos propomos realizar uma pesquisa narrando histórias tecidas por outras tantas histórias.

Por tudo isso, nos caminhos e descaminhos de nossas pesquisas, temos dialogado com Alves, Garcia, Certeau, Morin, Oliveira, Benjamin, Guimarães, entre outros, que problematizam os modelos tradicionais de pesquisa inventando possibilidades de registros e

\footnotetext{
${ }^{3}$ Para Certeau (1994, p. 151), "Subindo, descendo e girando em torno dessas práticas, algo escapa sem cessar, que não pode ser dito nem 'ensinado', mas deve ser 'praticado' [...] É um dizer aquilo que o outro diz de sua arte, e não um dizer dessa arte.
} 
de discussões que buscam, em última instância, nos aproximar do vivido, levando-nos a considerar as múltiplas produções dos sujeitos que praticam os cotidianos e que, por vezes, desafiam os limites das teorias que inicialmente considerávamos como "porto seguro", fazendo com que funcionem, tão somente, como portos de breves ancoragens.

De fato, em nossas pesquisas, afirmamos a potência dos diferentes sentidos enunciados pelos protagonistas dos cotidianos, não por boa vontade ou gratidão (FERRAÇO, 2003), mas pela crença nos processos que falam das vivências, das multiplicidades, das singularidades das relações cotidianas, das possibilidades que experimentamos de criarmos $e$ recriarmos a nós mesmos e o mundo (MATURANA, 2001).

\section{Algumas problematizações dos currículos e formações tecidas nos cotidianos de escolas}

Diferente de um trabalho que parece elementar, repetitivo, monótono, desprovido de imaginação, como muitos ainda argumentam, nossa convicção é de que as tessituras curriculares e formações de professores não se constituem em "mera repetição de saberesfazeres pedagógicos produzidos a partir de um determinado a priori do pensamento científico-moderno, de certo saber instituído que constituí um modo de ser professor [...]” (FERNANDES; COSTA, 2016, p. 99).

Essa aposta política de pesquisa rejeita certos discursos hegemônicos que colocam currículos e processos de formação como homogeneidades e padronizações, e aponta as artes de fazer (CERTEAU, 1994) dos professores como uma força de uma arte invisibilizada, criada no serviço da docência, que extrapola as previsões e prescrições feitas pelas políticas oficiais de currículos e de formações de professores. Usando uma metáfora de Certeau (1996), essas práticas vão sempre além do tempo teórico de cozimento indicado na receita, ou seja, de um tempo sequenciado, de objetivos e conteúdos pré-estabelecidos.

De modo semelhante aos alunos que marcam e alteram com seus usos os livros e mochilas, os uniformes e cadernos, as carteiras, as paredes e portas dos banheiros, esses praticantes da docência modificam os planejamentos, os livros didáticos, as propostas curriculares, os materiais e projetos que chegam às escolas e também aqueles que são criados nas redes de fazeressaberes (ALVES, 2001) produzidas e negociadas nos cotidianos dessas escolas. Desse modo, protagonizam nessas redes sua existência de autor (CERTEAU, 1994). Vão produzindo uma teoria das práticas (CERTEAU, 1994) nas tessituras cotidianas dos currículos e formações produzidas dentrofora (ALVES, 2010) das escolas, entre movimentos táticos e estratégicos de sujeitos praticantes. 
Assim, apoiados nesse pensamento certeauniano, referimo-nos às teorias das práticas como políticas do cotidiano. Sem negar as políticas educacionais elaboradas em outros espaçostempos da educação, interessa-nos os processos microbianos, plurais, operatórios, "o fraseado devido à bricolagem, à inventividade 'artesanal', à discursividade que combinam esses elementos, todos 'recebidos' e de cor indistinta" (GIARD, 1994, p. 15-16) que colorem e encharcam de vidas os cotidianos escolares.

Processos que não estão aqui nem lá, mas que se passam entre os limites estabelecidos e, sorrateiramente, desenham em trajetórias variáveis os cotidianos de escolas... Práticas-políticas produzidas em "águas" que se insinuam por toda a parte, que circulam sem serem vistas nesses cotidianos, que se deslocam e aos poucos vão erodindo os materiais impostos pelo modelo de produção, pelas práticas de consumo que se contentam em classificar, calcular e homogeneizar (CERTEAU, 1994).

Assim, apostando nessas artes das aulas e afirmando nossa atitude ético-política de pesquisa, fomos ao encontro desses professores e professoras, sujeitos anônimos das salas de aula, como uma tentativa de trazer à cena essas possibilidades de pensarfazer os currículos e os processos de formação de professores, a partir do que eles fazem e do que têm a nos contar...

Meu nome é Iara. Trabalho com o Ensino Fundamental desde 1987 e percebo que, a cada ano iniciado, volto com a mesma disposição (ou posso dizer, até maior). Acredito que isso faça muita diferença no resultado de qualquer experiência... Entendo que o sucesso de uma proposta pedagógica de trabalho dependa, em grande parte, da relação professor-aluno. Quando essa relação é baseada na afetividade e no respeito mútuo, a chance de um bom resultado é bem maior...

Partindo de sua aposta nas relações e afetos com os estudantes como elementos da docência, Iara continua...

No cotidiano escolar, não gosto de trabalhar com projetos, principalmente os que já vêm prontos, não considerando a realidade da turma. Grandes atividades desenvolvidas em minhas aulas foram 'sementinhas' que foram crescendo gradativamente. $\mathrm{O}$ trabalho, com poemas, por exemplo, divulgado em 'A Gazetinha', tomou uma proporção maior do que o esperado. As propostas iam sendo feitas e a turma correspondia, aceitando-as ou dando novas sugestões. O resultado foi ótimo! Só quem acompanhou pode perceber sua influência na questão da autoestima daquelas crianças.

João, professor de Educação Física, trabalha com diferentes turmas em uma mesma escola e, como muitos outros docentes brasileiros, desloca-se diariamente para outros municípios cumprindo dois turnos de trabalho. Ele também nos contou sobre o trabalho que faz.. 
[...] Olha só! Eu pego essa parte das diretrizes dos professores de educação física e vou adaptando, porque não dá para todos os alunos. Tem coisas que os alunos não gostam muito e aí mudo com eles. Além disso, acrescento sempre uma conversa sobre a organização da turma, o respeito pelo outro, sobre as faltas e os valores porque acho que isso está faltando muito hoje em dia.

Para dar conta de uma produção curricular e de processos de formações com seus alunos, entendendo que as docências extrapolam os espaços escolares, ele faz algumas tentativas...

Às vezes, faço uma roda na quadra só para conversar com eles e combinar essas coisas. Tem alunos que as famílias nem ligam, então é preciso... [...] Eu vou fazendo assim, procuro conversar muito com eles para envolvê-los e também estou sempre pela escola com eles... Tenho essas anotações que faço junto com eles: respeito, organização, amizade, participação nas aulas, faltas. Uso para avaliar, entendeu? Vamos lendo e comentando cada coisa e aí sinto que eles se envolvem mais... [...] Eu prefiro decidir as coisas com eles...

Desse modo, ouvindo o que esses praticantes das aulas dizem sobre suas artes de fazer, começamos a entender que nos trançados da docência essas políticas de currículo e formação se multiplicam, se tecem ao mesmo tempo e com todos. Ao contar suas práticaspolíticas cotidianas, esses habitantes-artistas desdenhados pelos engenheiros-terapeutas da cidade (CERTEAU, 1996, p. 198) nos dão pistas de que quando nos propomos a pensar currículos e processos de formação continuada de professores a partir do que é realizado (FERRAÇO, 2005) nos cotidianos escolares, esses processos vão se embolando nas teias das relações das salas de aula. Nos cotidianos, as aulas de Iara e de João, que se entrelaçam a tantas outras, são inventadas, mostrando, para quem estiver disposto a ver, os jeitos singulares de fazer desses professores que, como inventores de trilhas nas selvas da racionalidade (CERTEAU, 1994), ampliam essas redes e traçam trajetórias indeterminadas nos cotidianos das salas de aula e das escolas.

Contrariando, de certo modo, o que se tem sido priorizado nas políticas oficiais de currículos e de formações de professores, apostamos e temos interesse por essas artes de fazer as aulas que se insinuam e se inventam (CERTEAU, 1994) nas tramas das redes de saberes, fazeres, afetos, sentidos, valores, poderes, significados, entre tantas outras.

Afirmando a importância de ouvir os praticantes da escola que, com suas narrativas, ajudam-nos a compreender a complexidade dessas redes cotidianas, continuamos perseguindo as orientações de Certeau (1994) que não dissocia a arte de dizer de uma arte de fazer e de pensar, portanto, é ao mesmo tempo a prática e a teoria dessa arte. Sendo assim, nos rastros dessas práticas comuns, usamos as narrativas das aulas como artes praticadas, que em meio 
às artimanhas, aos jogos de linguagem, aos efeitos sonoros, às palavras inventadas e deformadas, às misturas... vão nos encaminhando para várias e incontroláveis direções.

Artes que também nos dão pistas das fragilidades das políticas oficiais de educação diante da complexidade dessas práticas-políticas que são vividas nas escolas e de seus distanciamentos. Práticas-políticas que incorporam os imprevistos, os acasos, as incertezas, as relações de forças, os afetos, os valores e os jeitos de fazersaber desses praticantes como fios desse entremeado de redes que se tecem para todos os lados, dentrofora (ALVES, 2010) das escolas, nos intercâmbios dos diferentes contextos de formação e de produção curricular, alargando nossas possibilidades de pensarfazer esses processos de outros modos, diferentes dos modelos "autorizados" e historicamente considerados "válidos".

Falamos, nesse sentido, de artes de dizer, conversações, relatos e narrativas que nas pesquisas com os cotidianos (FERRAÇO, 2003) são pensadas, sobretudo, como redes dessas práticas-políticas que se entrecruzam compondo diferentes histórias, sem autorias individuais, tecidas aos fragmentos e provocando alterações nos múltiplos espaçostempos habitados.

Continuando as conversas com professores, pistas de encantamento e de tentativas de expansão curricular foram surgindo...

Esse ano fizemos um projeto interdisciplinar bem legal! Juntamos as áreas de Humanas, de Linguagens e de Matemática e criamos um projeto para discutir junto aos alunos diversos temas, como: relações e direitos humanos, respeito aos idosos, alimentação, qualidade de vida, meio ambiente... $\mathrm{Na}$ verdade, como a pedagoga alertou, são temas propostos pelos PCN's e DCN's, mas a gente vai além dessas orientações... Resolvemos trabalhar esses temas porque achamos mesmo que são relevantes na vida dos nossos meninos e meninas e que nem sempre são discutidos com a devida importância. E mais: quando eles criam, põem a "mão na massa", os conhecimentos se ampliam muito, acho que é porque faz sentido pra eles.

E, no encontro das aulas, as invenções curriculares praticadas na docência ganham força...

[...] Eles fizeram trabalhos muito interessantes e muito bonitos, com capricho! Foram maquetes, murais, jornais, histórias em quadrinhos, charges, montagem de blog, entre muitas outras coisas... Organizamos também algumas apresentações orais de poemas, crônicas e textos, além de um concurso de peças teatrais [...] Fizemos também duas "sessões de cinema" com documentários que se relacionavam aos temas discutidos, um deles foi você que emprestou lembra? [...] Os meninos têm muito potencial, a gente que precisa ajudar a canalizar, às vezes. Acho que isso é currículo, como você vive dizendo, não é?! 
Os estudantes também contam das experiências que criam nas escolas... Currículos e processos de formações disparados em tantas direções...

Tem muita coisa que acontece também porque os próprios alunos inventam, assim, mas com a ajuda das coordenações, dos professores e com o trabalho do Grêmio! São as atividades que a gente chama de culturais, mas que aprendemos muito também, como sarau, exposição, teatro, aula de dança, show de talentos, varias coisas... e começa lá na Semana de Acolhida, logo que a gente chega... Alguém já falou sobre isso?!?! Eu quero falar... é que a gente já começa aprendendo a se relacionar melhor com as pessoas, a respeitar, a colher o que planta, literalmente, porque a gente faz o plantio de árvores! [Risos...] Ah! São atividades que fazem a gente aprender a conviver e a gostar de estar aqui na escola.

Redes que se tecem para todos os lados numa incessante tessitura de afetos, companheirismos, solidariedades e "invencionices" ...

No bimestre que acabou nós também tivemos uma atividade bem legal [...] Foi sobre a questão do lixo na escola [...] nós fizemos o recolhimento do lixo que é jogado em vários pontos do campus, fora das lixeiras, claro! E depois com a ajuda dos professores de Matemática e Estatística fizemos vários cálculos... Simulamos a quantidade de lixo que seria produzida em dias, meses e até no ano inteiro. Depois montamos gráficos e apresentamos uma proposta pra Direção da escola, pedindo a instalação de mais lixeiras, em vários pontos do campus e que foram localizados pelo mapa, através do Google. Ficou bem legal... Lembra que apresentamos na Semana do Meio Ambiente? Foi um trabalho bastante elogiado, até porque nós também apresentamos numa área do pátio, uma boa quantidade de lixo que foi recolhida assim.. Chamou a atenção porque somos nós mesmos que produzimos e jogamos em local inapropriado, né?

Assim, em meio às experiências, às divergências, às criações, aos valores, às táticas e estratégias dos praticantes dentro do lugar próprio (CERTEAU, 1994), os movimentos vão se constituindo nas práticas desses praticantes e de tantos outros... Modos de dar aulas, de reinventar os espaços, de inventividades e de enfrentamento dos desafios diários que falam da complexidade dessas redes cotidianas e colocam em questão o status dos discursos teóricos que, muitas vezes, reprimem e desqualificam as produções dos praticantes das escolas, não levando em consideração tantos saberesfazeres que potencializam e ampliam os sentidos da escola, provocando outros modos de convivência entre alunos/as e professores/as. Práticas que funcionam como operações enunciadoras dos diferentes tipos de relações e percursos que as trajetórias cotidianas implicam (CERTEAU, 1996).

Afinal, como Morin (2007, p. 6) nos ensinou...

[...] a complexidade surge, é verdade, lá onde o pensamento simplificador falha [...]. Enquanto o pensamento simplificador desintegra a complexidade do real, o pensamento complexo integra o mais possível dos modos 
simplificadores de pensar, mas recusa as conseqüências mutiladoras, redutoras, unidimensionais e finalmente ofuscantes de uma simplificação que se considera reflexo do que há de real na realidade.

Portanto, nosso pensamento se encaminha para a compreensão de que as políticas cotidianas de educação se constituem nas articulações, nos enredamentos e nas interpenetrações que se dão entre as políticas locais e globais, macro e micro, entendendo que todos esses processos se tramam a partir das experiências diferenciadas dos sujeitos que praticam os cotidianos, em suas relações de saber e poder, nas tensões, contradições e lutas. Processos que mostram a força do político nos estudos dos cotidianos, que evidenciam uma politização do cotidiano (CERTEAU, 1995).

\section{Pistas para pensar outras tessituras curriculares e de formações de professores}

A partir das questões teórico-metodológico-políticas já explicitadas, as práticaspolíticas dos praticantes são consideradas como potências na produção de saberesfazeres que, na cotidianidade das escolas, indicam os processos inventivos efetivados em redes compartilhadas. Assim, as experiências das pesquisas são marcadas especialmente por essas redes tecidas pelos alunos e professores das escolas públicas, buscando uma aproximação das marcas deixadas nos currículos e os movimentos de formações docentes produzidos a partir das experiências nos múltiplos espaçostempos de vida e das relações estabelecidas com os variados contextos cotidianos desses praticantes.

Considerando essas circunstâncias e partindo dos mergulhos realizados nas diferentes temporalidades e espacialidades das escolas públicas envolvidas em nossas pesquisas, procuramos dar visibilidade aos processos que afirmam a força das redes tecidas pelos sujeitos comuns (CERTEAU, 1994) que inventam as escolas, afirmando a possibilidade da criação de outras lógicas e de outros mundos nas relações com os conhecimentos que circulam nesses cotidianos.

Vale lembrar também que na produção dos dados utilizamos imagens, narrativas, entrevistas, documentos, bilhetes, conversas, planejamentos de aulas e outras pistas, para além da ideia de fontes, ou seja, como forma de aproximação e diálogo com os sujeitos que tecem a memória desses espaçostempos, a partir do que lembram, do que têm a dizer e a contar sobre o que fazem e/ou já fizeram.

Com esses "fragmentos" colocados no texto, retomamos a ideia de que os conhecimentos não são criados apenas naquelas oportunidades consagradas pela escola diante dos saberes formalizados da ciência, mas surgem a partir das relações, sendo criados na 
multiplicidade de encontros, desencontros, significações, contextos. São, portanto, múltiplas as possibilidades de contato, de redes e de surgimento de diferentes saberes que cotidianamente são tecidos, embolados, desmanchados, ressignificados. Currículos e formações que surgem e se criam nos constantes movimentos dessas redes.

Damo-nos conta, assim, que esses processos criadostecidos com os fios das múltiplas práticas cotidianas desses praticantes interligam as histórias dessas pessoas aos seus contextos de vida e à infinidade de experiências que os constituem. São ainda práticas que, para Alves (2002), devem "fazer emergir as tantas redes trançadas cotidianamente" (p. 57) nas escolas e que, em muitas ocasiões, não são consideradas, mesmo "sabendo" que esses praticantes chegam às escolas prenhes dessas redes.

Desse modo, compreendemos que são os sujeitos individuaiscoletivos (FERRAÇO, 2004) que imprimem suas marcas e articulam contextos religiosos, familiares, culturais, sociais e políticos, realizando suas práticas na efemeridade do cotidiano. E, nesses momentos em que praticam as diferentes redes de saberesfazeres nas escolas, aparecem como sujeitos cotidianos que inventam currículos (FERRAÇO, 2004) e processos de formação. Por isto, para nós, pensar currículos e formações de professores/as só faz sentido se consideradas as redes de saberes, fazeres, poderes, valores e sentidos que se trançam nos múltiplos cotidianos que pertencemos.

Parece também urgente provocar um pouco mais os debates sobre os sentidos, os caminhos e a necessária revisão do modelo de escola pública, "considerando-se sua formação histórica e as tendências culturais, políticas e econômicas" que falam da crescente complexidade da educação (LINHARES, 1999). Problematizar certos discursos que naturalizam a negação e a desqualificação da escola pública parecendo desconhecê-la como espaçotempo de resistências, de lutas e de produção de formas múltiplas de sobrevivência, de alternativas escolares/pedagógicas/políticas; como fruto de diferentes práticas de sujeitos históricos, sociais, culturais e políticos que não renunciam à dignidade da emancipação humana (LINHARES; NUNES, 2000). Sem contar que o discurso da negação da escola pública procede a um verdadeiro "assassinato cultural", à medida que silencia e emudece os sujeitos que acabam por ocupar lugares subalternizados, "definidos por processos globalizadores, que vão sendo operados à nossa revelia” (LINHARES, 1999).

Contribuindo e alargando essas possibilidades de análise, Certeau (1995, p. 9) vai nos dizer sobre a urgência de "[...] se desviar das generalizações apressadas e vagas, dos lugares-comuns que haviam durante muito tempo servido de doutrina oficial da ação cultural”. E também nos alerta sobre o fato de que “[...] nenhuma ação cultural ou política que 
seja inventiva e apoiada no real pode nascer da deficiência do pensamento ou se alimentar do desprezo do próximo".

Assim, reconhecer as ambiguidades e a pluralidade de possíveis vivências e interpretações, desfiar as teias de relações cotidianas, fugir dos dualismos e polaridades e questionar as dicotomias, recuperando a dimensão histórica que possibilita perceber suas mudanças e permanências, descontinuidades e fragmentações, as amplas articulações, as infinitas possibilidades dessa trama multidimensional, que se compõe e recompõe continuamente (MATOS, 2002, p. 27), são orientações que acolhemos e que ampliam nosso modo de pensar as políticas a partir das teorias do cotidiano.

Nesse sentido, estar nos cotidianos de escolas realizando pesquisas que não se pretendem explicativas, conclusivas ou receituárias, mas que desejaram ir ao encontro daqueles/as responsáveis pela multiplicidade das práticas-políticas realizadas, não foi e não é uma tarefa fácil de ser cumprida. Talvez porque ao invés de permanecer no terreno de um discurso totalizante, tais investigações pretendem apontar outras possibilidades de falar das redes de conhecimentos que constituem as práticas escolares, falar da beleza e multiplicidade dessas redes de fazeressaberes, apesar das mazelas ainda existentes. Desdobramentos de um modo de pensar aprendido com a ciência moderna que trata o cotidiano como enfadonho, repetitivo, sem valor e que aponta a manutenção da relação de dominação/submissão quando/onde se evidencia, muitas vezes, o excesso de regulação em detrimento da emancipação (SANTOS, 2001).

Assim, por estarmos imersos nessas redes, consideramos que os currículos e os processos de formação se constituem nas dinâmicas das relações cotidianas, nas diversas práticas que envolvem poder, discurso e criação de saberes e sentidos, e vão religando campos disciplinares que são desmembrados pelo pensamento simplificador. Um pensamento que desintegra a complexidade do real (MORIN, 2007) e vai produzindo outros sentidos e configurações nas políticas de educação.

\section{REFERÊNCIAS}

ALVES, Nilda. Artefatos tecnológicos relacionados à imagem e ao som na expressão da cultura de afro-brasileiros e seu "uso" em processos curriculares de formação de professoras na Educação Superior. Projeto incorporado ao PROCIÊNCIA, ago de 2005.

ALVES, Nilda. (Org.). Criar currículo no cotidiano. SP: Cortez, 2002.

ALVES, Nilda. Decifrando o pergaminho. In: OLIVEIRA, I. B. de; ALVES, N. (Org.).

Pesquisa no/do cotidiano das escolas. RJ: DP\&A, 2001. 
ALVES, Nilda. Redes educativas 'dentrofora' das escolas exemplificadas pela formação de professores. In: DALBEN, Â.; DINIZ, J.; LEAL, L.; SANTOS, L. (Org.). Convergências e tensões no campo da formação e do trabalho docente. Belo Horizonte: Autêntica, 2010.

ALVES, Nilda; GARCIA, Regina Leite. Atravessando fronteiras e descobrindo (mais uma vez) a complexidade do mundo. In: ALVES, Nilda; GARCIA, Regina Leite (Org.). O sentido da escola. Rio de Janeiro: DP\&A, 2002.

BENJAMIN, Walter. Magia e técnica, arte e política: ensaios sobre literatura e história da cultura. 3 ed. São Paulo: Brasiliense, 1987.

CERTEAU, Michel de. A cultura no plural. Campinas, SP: Papirus, 1995.

CERTEAU, Michel de. A invenção do cotidiano: 1: artes de fazer. RJ: Vozes, 1994.

CERTEAU, Michel de. A invenção do cotidiano: 2. morar, cozinhar. RJ: Vozes, 1996.

FERNANDES, Angela Maria D.; COSTA, Eduardo Antonio de Pontes. Formação docente e pesquisa inventiva: problematização, criação e intervenção nos cotidianos escolares. Espaço Pedagógico, Universidade de Passo Fundo, Faculdade de Educação, vol. 23, n. 1, jan./jun. 2016. Passo Fundo: UPF, 2016.

FERRAÇO, Carlos Eduardo. Eu, caçador de mim. In: GARCIA, R. L. Método: pesquisa com o cotidiano. RJ: DP\&A, 2003.

FERRAÇO, Carlos Eduardo. Currículo, formação continuada de professores e cotidiano escolar: fragmentos de complexidade das redes vividas. In: FERRAÇO, C. E. (Org.).

Cotidiano escolar, formação de professores (as) e currículo. SP: Cortez, 2005.

FERRAÇO, Carlos Eduardo. Os sujeitos das escolas e a complexidade de seus saberesfazeres: fragmentos das redes tecidas em pesquisas com o cotidiano. In: GARCIA, R. L.; ZACCUR, E. (Org.). Cotidiano e diferentes saberes. RJ: DP\&A, 2006.

FERRAÇO, Carlos Eduardo. Os sujeitos praticantes dos cotidianos das escolas e a invenção dos currículos. In: MOREIRA, A. F. B.; PACHECO, J. A.; GARCIA, R. L. (Org.).

Currículo: pensar, sentir e diferir. RJ: DP\&A, 2004.

FERRAÇO, Carlos Eduardo. Redes entre saberes, espaços e tempos. In: ROSA, Dalva E. Gonçalves; SOUZA, Vanilton Camilo de; VEIGA-NETO; et al. (Org.). Políticas organizativas e curriculares, educação inclusiva e formação de professores. RJ: DP\&A, 2002.

GIARD, Luce. História de uma pesquisa. In: CERTEAU, Michel de. A invenção do cotidiano: 1. Artes de fazer. Petrópolis, RJ: Vozes, 1994.

GUIMARÃES, César. O ordinário e o extraordinário das narrativas. In: GUIMARÃES, César; FRANÇA, Vera. (Org.). Na mídia, na rua: narrativas do cotidiano. Belo Horizonte: Autêntica, 2006. p. 8-17.

LINHARES, Célia Frazão. Escola Balaia: um convite ao debate para reinvenção de Caxias. Caxias/MA: Caburé, 1999. 
LINHARES, Célia Frazão; NUNES, Clarice. Trajetórias de magistério: memórias e lutas pela reinvenção da escola pública. Rio de Janeiro: Quartet, 2000.

MATOS, Maria Izilda Santos de. Cotidiano e cultura: história, cidade e trabalho. Bauru, SP: EDUSC, 2002.

MATURANA, H. Cognição, ciência e vida cotidiana. BH: Ed. UFMG, 2001.

MORIN, Edgar. Introdução ao pensamento complexo. Porto Alegre: Sulina, 2007.

SANTOS, Boaventura de Souza. A crítica da razão indolente: contra o desperdício da experiência. São Paulo: Cortez, 2001.

SGARBI, P. Depois de aceitar o convite, fiquei esperando um “causo". In: AZEVEDO, J. G. de; ALVES, N. G. (Org.). Formação de professores: possibilidades do imprevisível. RJ:

DP\&A, 2004.

\section{SOBRE OS AUTORES:}

\section{Carlos Eduardo Ferraço}

Doutor em Educação pela Universidade de São Paulo (USP). Professor da Universidade Federal do Espírito Santo (UFES). Docente do Programa de Pós-Graduação em Educação. Membro do Grupo de Pesquisa Currículos, Cotidianos, Culturas e Redes de Conhecimentos. Bolsista de Produtividade em Pesquisa do CNPq. E-mail: ferraco@uol.com.br

\section{Danielle Piontkovsky}

Doutora em Educação pela Universidade Federal do Espírito Santo (UFES). Professora do Instituto Federal do Espírito Santo (IFES). Docente do Programa de Pós-Graduação em Educação Profissional e Tecnológica do IFES. É membro do Grupo de Pesquisa Currículos, Cotidianos, Culturas e Redes de Conhecimentos. E-mail: danipirelli@ig.com.br

\section{Maria Regina Lopes Gomes}

Doutora em Educação pela Universidade Federal do Espírito Santo (UFES). Professora da Universidade Vila Velha (UVV). Docente do Programa de Pós-Graduação em Segurança Pública, da Universidade Vila Velha. Membro do Grupo de Pesquisa Currículos-formação em redes, Cotidianos de escolas e Direitos Humanos. Membro do Grupo de Pesquisa Currículos, Cotidianos, Culturas e Redes de Conhecimentos. E-mail: regilodo@ hotmail.com 